\title{
Synthesis of 1,2,3,4-Bisiminofullerene and 1,2,3,4-Bis(triazolino)fullerene-On the Mechanism of the Addition Reactions of Organic Azides to [60]Fullerene
}

\section{Clifton K.-F. Shen, Hsiao-hua Yu, Chiun-Gung Juo, Kuo-Ming Chien, Guor-Rong Her, and Tien-Yau Luh*}

Dedicated to Professor Sunney I. Chan on the occasion of his 60 th birthday

Abstract: The reactions of organic azides with [60]fullerene have paved the way for the synthesis of adducts with a variety of structures. Treatment of [60]fullerene with 2,2-dibenzyl-1,3-diazidopropane (10) in refluxing chlorobenzene afforded three products, namely, $\mathbf{8}, \mathbf{9}$, and $\mathbf{1 1}$ in 18,25 , and $11 \%$ yields, respectively. Thermolysis of $9 \mathrm{a}$ in refluxing chlorobenzene gave a
40:54:6 mixture of 8,11 , and $\mathrm{C}_{60}$ in quantitative yield. No interconversion between 8 and 11 was observed. Whereas 11 was

\section{Keywords}

azide adducts - fullerenes - reaction mechanisms - regioselectivity $\cdot$ thermolysis stable towards thermolysis, $\mathbf{8}$ decomposed to $\mathrm{C}_{60}(35 \%$ yield $)$ on refluxing in chlorobenzene for $24 \mathrm{~h}$, but it did not produce any 11. This indicates that $9 a$ is an intermediate in the formation of $\mathbf{8}$ and $\mathbf{1 1}$. A general mechanism for the addition of azides to $\mathrm{C}_{60}$ is proposed. A similar mechanistic pathway is suggested for the thermolysis of 9 a.

\section{Introduction}

The reactions of organic azides with [60]fullerene have paved the way for the synthesis of adducts with a variety of structures. ${ }^{[1-9]}$ Two types of monoadduct, $\mathbf{1}^{[1]}$ and $\mathbf{2}^{[2]}$ have been obtained. The selectivity of this addition reaction appears to depend upon the reaction conditions. For example, a nitrene intermediate with an aryl or an acyl substituent, generated in situ by photo-

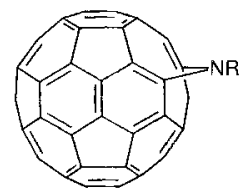

1

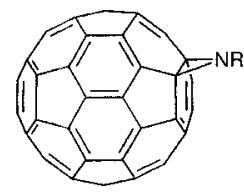

2

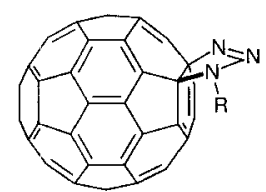

3 lysis of the corresponding azides or by other means, yields 2 exclusively. ${ }^{[2 \mathrm{f}, \mathrm{j}-\mathrm{l}]}$ Under thermolytic conditions, azides with an alkyl substituent add preferentially at the ring junction between five- and six-membered rings ([5,6] junction) to produce $\mathbf{1}$, whereas azide reagents with an alkoxycarbonyl substituent lead predominantly to 2 . On the other hand, the thermal reaction of an aryl azide with $\mathrm{C}_{60}$ can yield either $1^{[1 \text { a] }}$ or $2^{\left[{ }^{[e]}\right.}$ Interestingly, thermolysis of the triazoline adduct $\mathbf{3}$ gives $\mathbf{1}$ as the major, if not the exclusive, product. ${ }^{[21,3]}$

The situation is more complicated for bisadducts. Three distinct regioisomers of bisiminofullerenes have been obtained selectively, depending on the nature of the azide reagents. ${ }^{[3-9]}$ Wudl and co-workers have elegantly synthesized bisiminofullerene 4 by treating $\mathrm{C}_{60}$ with alkyl azides. ${ }^{[3,4]}$ Reactions with bisazides tethered by a partial fragment of a crown ether behave
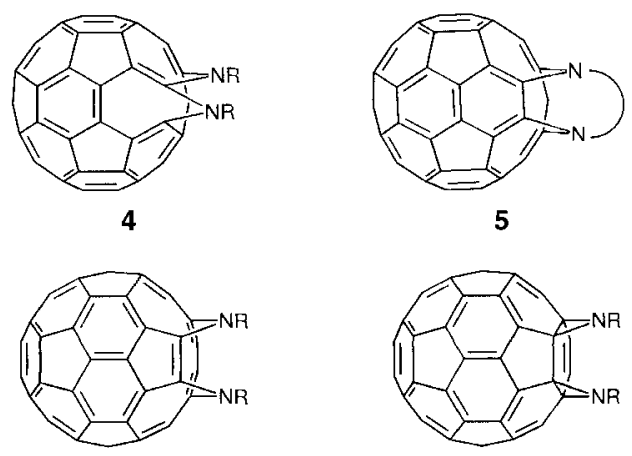

6

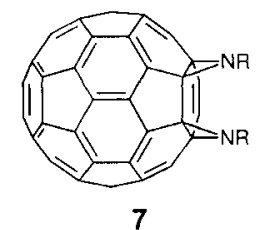

Fax: Int. code + (2) 363-6359

i-mail: tyluh(a coms.ntu.edu.tw 
similarly. ${ }^{[5]}$ The addition reaction occurs at the two $[5,6]$ junctions of an acenaphthene moiety in $\mathrm{C}_{60}$. In our preliminary communication, another type of bisiminofullerene, $\mathbf{5}$, was obtained from the reaction of $\mathrm{C}_{60}$ with a bisazide tethered by an ethylene or a trimethylene bridge. ${ }^{[6]}$ These azides add selectively at the two $[5,6]$ junctions of a fluorene unit in $\mathrm{C}_{60}$. Similar observations were made by $\mathrm{Li}$ and co-workers. ${ }^{[7]}$ Hirsch and co-workers reported a third type of adduct, $6\left(\mathrm{R}=\mathrm{CO}_{2} \mathrm{R}^{\prime}\right)$. Here the addition took place at the two ring junctions between six-membered rings $([6,6]$ junctions) of a phenanthrene unit in $\mathrm{C}_{60}$; this was followed by a ring-opening process. ${ }^{[8,9]} \mathrm{It}$ is interesting to note that none of these reactions lead directly to the formation of bisimino[60]fullerene 7. It is believed that 7, which may be formed initially, readily undergoes electrocyclic ring opening to produce 6 . Although AM 1 calculations suggest that the opened isomer $6\left(\mathrm{R}=\mathrm{CO}_{2} \mathrm{R}^{\prime}\right)$ is more stable than $7,{ }^{[8,9]}$ addition at the diene moiety of a six-membered ring in $\mathrm{C}_{60}$ has been well documented. ${ }^{[10]}$ More recently, Hirsch and co-workers examined the addition of alkoxycarbonylazides to $\mathrm{C}_{60}{ }^{[9]} \mathrm{In}$ addition to $6\left(\mathrm{R}=\mathrm{CO}_{2} \mathrm{Et}\right)$, six of seven other regioisomeric bisimino[60]fullerenes were isolated and characterized. Although $7\left(\mathrm{R}=\mathrm{CO}_{2} \mathrm{Et}\right)$ was not detected in this reaction, the corresponding parent bisimino[60]fullerene $7(\mathrm{R}=\mathrm{H})$ was obtained by treatment of $6\left(\mathrm{R}=\mathrm{CO}_{2} t \mathrm{Bu}\right)$ with trifluoroacetic acid. ${ }^{[9]}$ It was suggested that intermediate $7(\mathrm{R}=\mathrm{H})$ underwent an intramolecular Diels-Alder reaction. Apparently, the relative stability of 6 and 7 depends upon the substituent at nitrogen; this is also supported by theoretical calculations. ${ }^{[9]}$ As part of our continuing interest in the addition of azides to fullerenes, ${ }^{[2 d, 5]}$ we now report our investigation of the first direct synthesis of 1,2,3,4-bisimino[60]fullerene 8 and 1,2,3,4-bis(triazolino)[60]fullerene 9 and discuss a plausible mechanism of addition of azides to fullerene.

\section{Results and Discussion}

Our strategy is based on our previous work ${ }^{[6]}$ in which tethered bisazide reagents were added to $C_{60}$. Since the trimethylenebridged bisazide reacts with $\mathrm{C}_{60}$ to give the corresponding adduct 5 in satisfactory yield, ${ }^{[6]}$ it was felt that introducing a geminal dialkyl group at the $\mathrm{C} 2$ position of the trimethylene bridge would induce a change in the reactivity, so that the intermediate product might be isolated. Thus, $\mathrm{C}_{60}$ was treated with 1.5 equiv 2,2-dibenzyl-1,3-diazidopropane (10) in refluxing chlorobenzene for $8 \mathrm{~h}$; the standard workup procedure was then applied
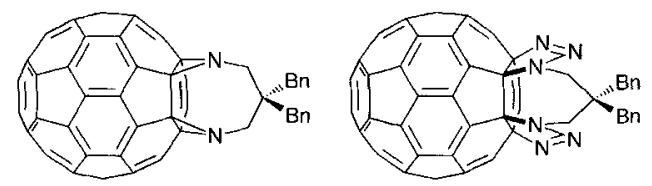

8

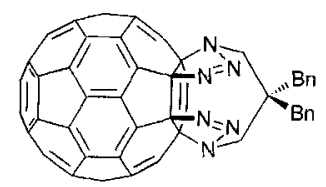

$9 b$

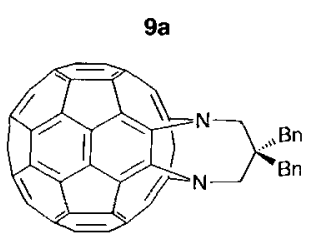

11 (see Experimental Section). Three products $\mathbf{8 , 9}$, and 11-were obtained in 18,25 , and $11 \%$ yields, respectively. The structural assignments were based on ${ }^{1} \mathrm{H}$ and ${ }^{13} \mathrm{C}$ NMR spectra (Figure 1) as well as on the mass spectral data. The UV/Vis spectra for 8 . $\mathbf{9}$, and $\mathbf{1 1}$ are shown in Figure 2.

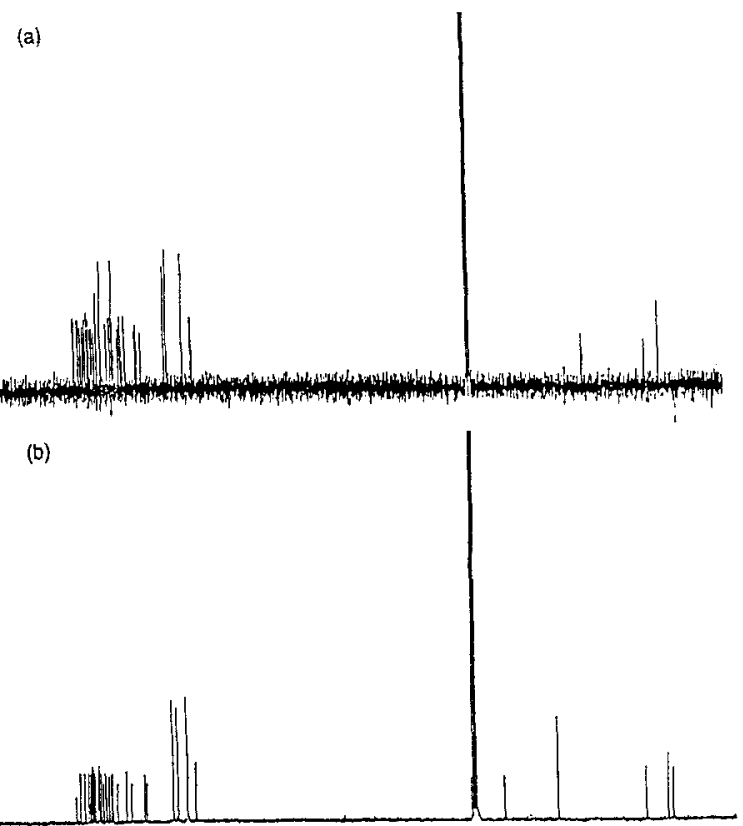

(c)

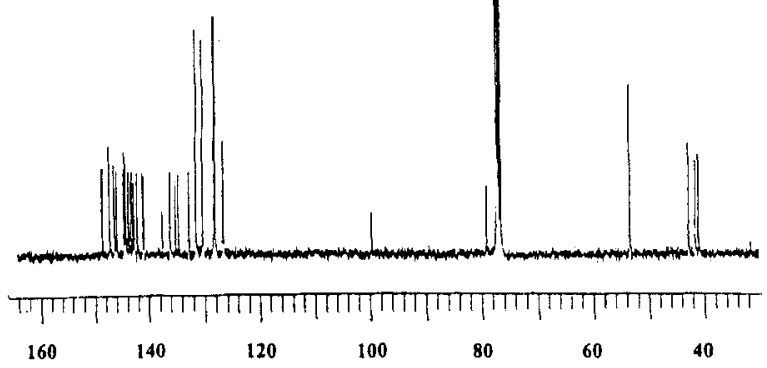

Figure 1. ${ }^{13} \mathrm{C}$ NMR spectra for a) 11, b) 8 , ind c) 9 .

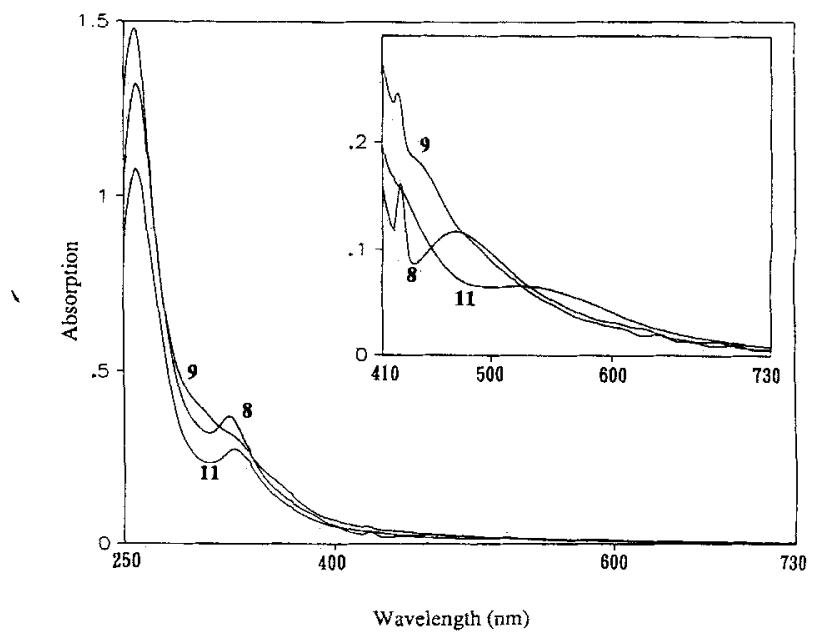

Figure 2. UV/Vis spectra for 11,8 , and 9 in $\mathrm{CHCl}_{3}\left(c=1.0 \times 10^{-5} \mathrm{moldm}^{-3}\right.$; inset: $c=5.0 \times 10^{-5}$ mol dm ${ }^{3}$ ). 
The absorption spectrum and the ${ }^{13} \mathrm{C}$ NMR spectrum for 11 are consistent with the structure given above and similar to those reported previously for $5 .{ }^{[6]}$ Both 8 and 9 exhibit absorptions at a $\lambda_{\max }$ of about $425 \mathrm{~nm}$, which is characteristic for adducts attached to a $[6,6]$ junction. The broad band at a $\lambda_{\max }$ of $470 \mathrm{~nm}$ for 8 can also be found in the UV/Vis spectra of iminofullerene derivatives $2 .{ }^{[2]}$ In the ${ }^{13} \mathrm{C}$ NMR spectrum of $\mathbf{8}$, the signals at $\delta=71.74$ and 77.63 , in addition to 30 peaks due to fullerene $\mathrm{sp}^{2}$ carbons, clearly indicate the presence of a fused bisaziridine moiety. These results are also in agreement with those for $7(\mathrm{R}=\mathrm{H}){ }^{[9]}$

The isolation of the bistriazolino adduct 9 is not only interesting, but also significant. In the ${ }^{13} \mathrm{C}$ NMR spectrum, the 30 signals arising from the fullerene $\mathrm{sp}^{2}$ carbons, in addition to the signals for the phenyl group and aliphatic carbons, are consistent with a $C_{\mathrm{s}}$ symmetry. The ${ }^{13} \mathrm{C}$ NMR absorptions for the two different fullerene $\mathrm{sp}^{3}$ carbons in 9 appear at $\delta=79.45$ and 99.82. In 3 the chemical shifts for $\mathrm{sp}^{3}$ carbons of this type fall within the range $\delta \approx 80-110$, depending on the nature of the substituent on nitrogen. ${ }^{[21,3,11]}$ Therefore, our results are in agreement with those already reported. Since the ${ }^{13} \mathrm{C}$ NMR data suggest that there is no ring opening in adduct 9 , we propose that addition has taken place at the $[6,6]$ junction. Owing to the rigidity of the tether, $\mathbf{9 a}$ or $\mathbf{9 b}$ would be feasible structures.

Since 3 has been suggested to be an intermediate leading to 1 and $2,{ }^{[2.3]}$ it seems likely that 9 could also be an intermediate in the formation of $\mathbf{8}$ and 11. Accordingly, thermolysis of 9 in refluxing chlorobenzene for $24 \mathrm{~h}$ afforded a 54:40:6 mixture of 8, 11, and $C_{60}[\mathrm{Eq} .(1)]$ in quantitative yield. It is noteworthy that there was no interconversion between 8 and $\mathbf{1 1}$. When $\mathbf{8}$ was refluxed for $24 \mathrm{~h}$ in chlorobenzene, $\mathrm{C}_{60}$ was produced in $35 \%$ yield, but no 11 was detected. There was no decomposition of 11 under the same conditions. These results suggest that 9 may be an intermediate in the formation of $\mathbf{8}$ and $\mathbf{1 1}$.

9

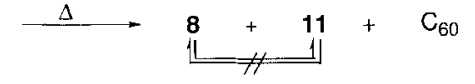

It is well documented that the $\mathrm{C}_{60}$ molecule behaves similarly to a [5]radialene in a number of addition reactions and that these double bonds are highly reactive. An enhancement in the reactivity would be expected for a bisazide 10 , which has a geminal dibenzyl group at C2. Stereochemically, the bisaddition reaction at two [6,6] junctions should occur preferentially to give 9 .

The mechanism for the thermolysis of triazolines has been investigated in detail. ${ }^{[12]}$ Dipolar and biradical intermediates have both been suggested. Cleavage of the $\mathrm{N}-\mathrm{N}$ single bond appears to precede cleavage of the $\mathrm{C}-\mathrm{N}$ bond in both mechanisms. Nevertheless, before we discuss the conversion of $\mathbf{9}$ to 8 and 11, we will present a possible mechanism for the thermolysis of triazoline 12 (Scheme 1).

A biradical intermediate $\mathbf{1 3}$ is expected from the thermal decomposition of $\mathbf{1 2}$. Two possible routes will lead to $\mathbf{1 5}(2)$ or $\mathbf{1 7}$ (1), depending on the timing of the liberation of nitrogen molecule from 13. If the cleavage of the $\mathrm{C}-\mathrm{N}$ bond in $\mathbf{1 3}$ is fast, then biradical 14 will be formed, producing 15 on recombination at the $\mathrm{C} 2$ position. On the other hand, the nitrogen-centered radi-

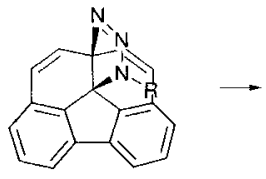

12

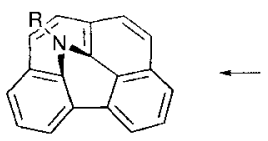

17

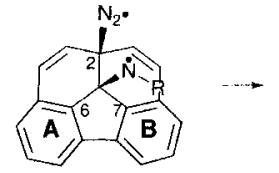

13
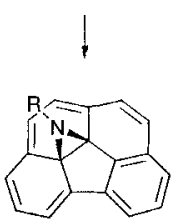

16

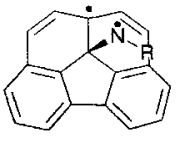

14

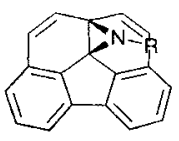

15
Scheme 1. Possible mechanism for the thermolysis of triazoline $\mathbf{1 2}$ (only relevant section of the fullerene is shown).

cal in $\mathbf{1 3}$ may add to $\mathrm{C} 6$ or $\mathrm{C} 7$ (equivalent in the monoadduct) before the departure of the nitrogen molecule, leading to addition at the $[5,6]$ junction to produce adduct 16. At this point it is worth mentioning that $\mathbf{1 6}$ could be the kinetic product, because aromaticity of an additional six-membered ring moiety (ring A or B) will be lost with its formation. However, a rapid ring opening in $\mathbf{1 6}$ then yields stable $\mathbf{1 7 .}$

The possible route for the thermolysis of $\mathbf{9}$ is similar to that described in Scheme 1. ${ }^{[12]}$ The two triazoline heterocycles may not decompose simultaneously. Since the three-carbon tether in 9 is quite rigid, the nitrogen-centered radical produced may not be as labile as that in 13. Accordingly, there are several possibilities for the fate of the two nitrogen-centered radicals in $\mathbf{1 8}^{[13]}$ generated stepwise from 9 a (Scheme 2). The formation of the first aziridine ring may lead to two delocalized biradicals, 19 and
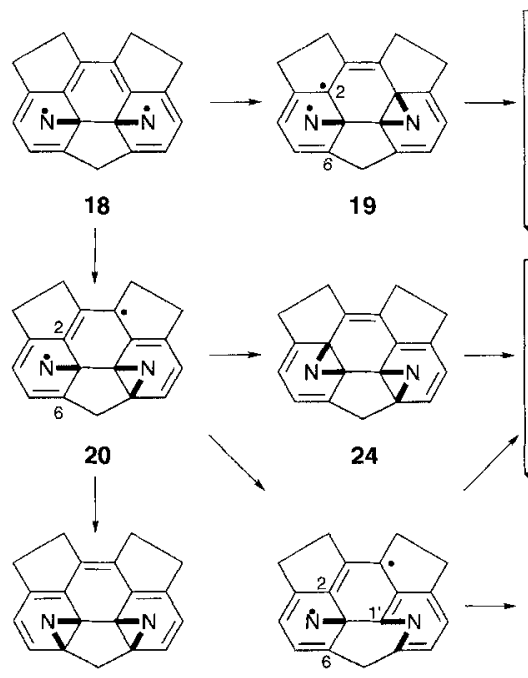

19

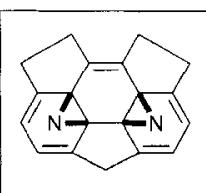

8
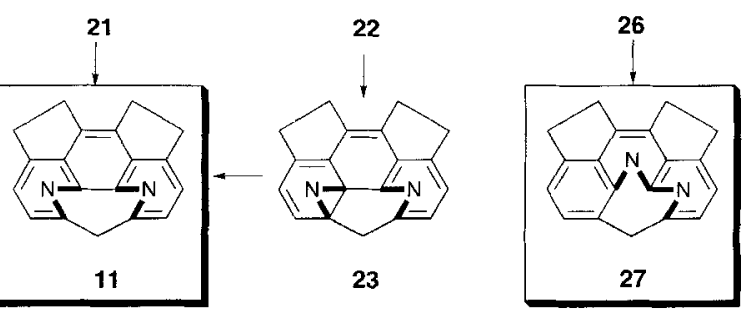

Scheme 2. Possible reactions of the biradical species 18 (only relevant section of the fullcrene is shown; substituents at nitrogen omitted for clarity). 
20. Collapse of the biradical 19 by attack at $\mathrm{C} 2$ would yield 8 . In a similar manner, radical recombination at $\mathrm{C} 6$ in 20 would lead to 21 . Since the structure produced by ring closure at the $[5,6]$ junction would be highly unstable, ${ }^{[2 \mathrm{i}]}$ a simple ring opening of 21 would then yield 11 . Alternatively, there may be an initial ring opening of the aziridine moiety in $\mathbf{2 0}$ to give $\mathbf{2 2}$. Further collapse of the biradical 22 by attack at $\mathrm{C} 6$ would give intermediate 23 , followed by another ring opening to produce 11 . It appears that the orientation of the aziridine ring that forms first might have a directing effect on the regioselectivity of the second aziridine ring. Recombination of biradicals 19 and $\mathbf{2 0}$ could also occur by different pathways and could eventually lead to the formation of further possible isomers 25 and 27 (Scheme 2). Since the two nitrogen atoms are tethered by a relatively rigid three-carbon chain, collapse of the biradical $\mathbf{2 0}$ or $\mathbf{2 2}$ by attack at $C 2$ leading to $\mathbf{2 4}$ or $\mathbf{2 5}$, respectively, might not be favorable. The absence of $\mathbf{2 7}$ from this reaction is striking. Presumably, in 20 or 22 the $\mathrm{N}_{2}$ moiety may still be attached to $\mathrm{C} 2$, as in 13, before collapse. A mechanism similar to the decomposition of 13 may occur here to produce 11. Furthermore, the intermediate leading to 4 or 27 has been shown to be different from $9 .^{[3]}$

Decomposition of $\mathbf{9 b}$ by a mechanism similar to that proposed in Scheme 2 would give 8 and 29 (Scheme 3). After ring opening, 29 would be converted into $\mathbf{3 0}$, which was not detected. Accordingly, the most likely structure for $\mathbf{9}$ is $\mathbf{9 a}$.

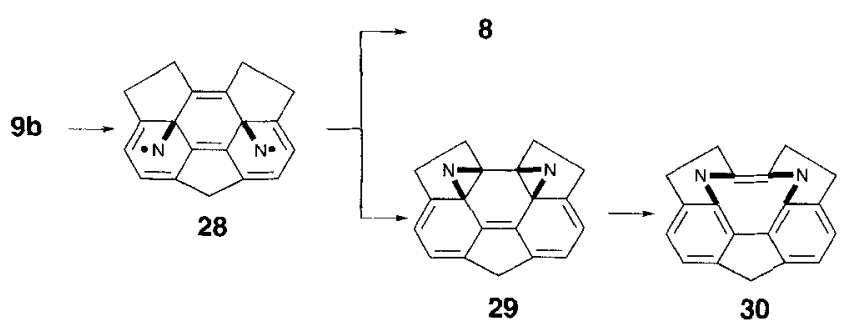

Scheme 3. Possible decomposition reactions of $\mathbf{9 b}$ (only relevant section of the fullerene is shown: substituents at nitrogen omitted for clarity)

\section{Conclusion}

We have described the first direct synthesis of bisimino[60]fullerene 8,11 , and bis(triazolino)[60]fullerene 9, from the reaction of $\mathrm{C}_{60}$ and the corresponding bisazide. It has been established that 9 is an intermediate in the formation of 8 and 11. These results serve as a useful clue to the understanding of the actual mode of the overall transformation in the addition of azides to $C_{60}$. A general mechanism has been proposed to explain the different regioselectivities for the addition of organic azides to [60]fullerene. Furthermore, the isolation of adduct 8 supports results from calculations performed by Hirsch, which indicate that the alkyl substituent on nitrogen would favor the bisring-closure product. ${ }^{[9]}$

\section{Experimental Section}

2,2-Dibenzyl-1,3-propanediyl dimesylate: To a solution of 2,2-dibenzyl-1.3propanediol $(2.56 \mathrm{~g}, 10.0 \mathrm{mmol})$ and $\mathrm{Et}_{3} \mathrm{~N}(4.0 \mathrm{~g}, 40 \mathrm{mmol})$ in $\mathrm{CH}_{2} \mathrm{Cl}$, $(30 \mathrm{~mL})$ at $0^{\circ} \mathrm{C}$ was added dropwise a solution of $\mathrm{MsCl}(4.0 \mathrm{~g}, 35 \mathrm{mmol})$ in
$\mathrm{CH}_{2} \mathrm{Cl}_{2}(25 \mathrm{~mL})$ over a period of $40 \mathrm{~min}$. The mixture was allowed to warm to RT and stirred for $12 \mathrm{~h}$. Aqueous $\mathrm{HCl}(10 \%, 50 \mathrm{~mL})$ was added and the organic layer washed with $\mathrm{NaOH}(10 \%)$ and water. The organic layer was dried $\left(\mathrm{MgSO}_{4}\right)$ and evaporated in vacuo. The residue was recrystallized from methanol to give a white solid (2.68 g. 65\%). M.p.: $124125{ }^{\circ} \mathrm{C}:{ }^{1} \mathrm{H}$ NMR $\left(\mathrm{CDCl}_{3}, 300 \mathrm{MHz}\right): \delta=2.81(\mathrm{~s}, 4 \mathrm{H}), 2.99(\mathrm{~s}, 6 \mathrm{H}), 4.00(\mathrm{~s}, 4 \mathrm{H}), 7.19-7.35$ $(\mathrm{m}, 10 \mathrm{H}) ;{ }^{13} \mathrm{C} \mathrm{NMR}\left(\mathrm{CDCl}_{3}, 75 \mathrm{MHz}\right): \delta=37.31,38.18,42.15,69.58$, 127.20, 128.62, 130.59, 135.04: IR (KBr): $\hat{v}=1598,1494,1461,1413,1387$. $1360,1333,1328,1281,1267.1172 .1051,1030,983.948 .885 .865,824.775$, $751,733,704 \mathrm{~cm}^{-1}$ : HRMS caled for $\mathrm{C}_{19} \mathrm{H}_{24} \mathrm{O}_{6} \mathrm{~S}_{2}: 412.1014$ : found 412.1010

2,2-Dibenzyl-1,3-diazidopropane (10): To a solution of the dimesylate prepared above $(0.62 \mathrm{~g}, 1.5 \mathrm{mmol})$ in DMF $(40 \mathrm{~mL})$ and [15]crown-5 (one drop) was added $\mathrm{NaN}_{3}(0.39 \mathrm{~g}, 6 \mathrm{mmol})$ and water $(1 \mathrm{~mL})$. The mixture was $\mathrm{re}$ fluxed for one day then quenched with water $(50 \mathrm{~mL})$. The solution was extracted with ether and washed twice with water. The ether was evaporated in vacuo to afford 10 as a colorless viscous oil $(0.25 \mathrm{~g} .55 \%)$, which wals used for the next reaction without further purification: ' $\mathrm{HNMR}\left(\mathrm{CDCl}_{3}\right.$. $200 \mathrm{MHz}): \delta=2.70(\mathrm{~s}, 4 \mathrm{H}), 3.06(\mathrm{~s}, 4 \mathrm{H}), 7.26(\mathrm{~m}) ;{ }^{1.3} \mathrm{C} \mathrm{NMR}\left(\mathrm{CDCl}_{3}\right.$, $50 \mathrm{MHz}): \delta=39.30,42.82,54.06,126.72 .128 .41,130.62 .136 .43 ; \mathrm{IR}(\mathrm{KBr}):$ $\tilde{i}=2100 \mathrm{~cm}^{-1}$

Reaction of 10 with $\mathrm{C}_{60}$ : To a refluxing solution of $\mathrm{C}_{60}(360 \mathrm{mg}, 0.5 \mathrm{mmoi})$ in chlorobenzenc $(360 \mathrm{~mL})$ under $\mathrm{N}_{2}$ was added dropwise bisizide 10 $(0.75 \mathrm{mmol})$ in chlorobenzene $(100 \mathrm{~mL})$. The mixture was refluxed for $68 \mathrm{~h}$ and monitored by TLC. The solvent was removed in vacuo and the residue was repetitively chromatographed on silica gel to give three products 8 (85 $\mathrm{mg}, 18 \%), 9(153 \mathrm{mg}, 25 \%)$, and $11(51 \mathrm{mg} .11 \%)$

8: ${ }^{1} \mathrm{HNMR}\left(\mathrm{CS}_{2} / \mathrm{CDCl}_{3}, 300 \mathrm{MHz}\right): \delta=2.86(\mathrm{~s}, 2 \mathrm{H}), 3.86(\mathrm{~d}, J=12.5 \mathrm{~Hz}$. $2 \mathrm{H}), 3.91(\mathrm{~s}, 2 \mathrm{H}), 4.48(\mathrm{~d}, J=12.5 \mathrm{~Hz}, 2 \mathrm{H}), 7.20-7.71(\mathrm{~m}, 10 \mathrm{H}):{ }^{13} \mathrm{C} N \mathrm{NR}$ $\left(\mathrm{CS}_{2} / \mathrm{CDCl}_{3}, 100 \mathrm{MHz}\right): \delta=41.06,42.00,45.88,61.98,71.74,77.63,126.90$. $126.96,128.43,128.48,130.15,131.02,135.71 .136 .11,138.47,139.41,139.43$. $141.00,141.88,141.99,142.17,142.48,142.59,142.89,143.02,143,17,143.55$, $143.91,143.95,144.17,144.31,144.33,144.44,145.07,145.32,145.38,145.49$, $145.51,145.73,145.90,146.21,146.93,147.78,148.52$ : UVVis $\left(\mathrm{CHCl}_{3}\right): i_{\max }$ $\left(\varepsilon \times 10^{-3} \mathrm{~L} \mathrm{~mol}^{-1} \mathrm{~cm}^{-1}\right)=689(0.3), 652(0.3), 625(0.5), 470(2.4), 425(3.2)$, $325(36.9), 259(131.8) \mathrm{nm} ; \mathrm{IR}(\mathrm{KBr}): \tilde{v}=2366.2344,1656.1511 .1494 .1450$. $1457,1439,1426,1408,1400,1363,1344,1315,1305,1260,1248,1214,1180$, $1156,1115,1084,1071.1062,1030.760,744,729.701 .648 \mathrm{~cm}^{1}{ }^{1}:$ FABMS: 970.8 .

9: ${ }^{1} \mathrm{HNMR}\left(\mathrm{CS}_{2} / \mathrm{CDCl}_{3}, 300 \mathrm{MHz}\right): \delta=2.78(\mathrm{~s}, 4 \mathrm{H}), 3.64(\mathrm{~s} .4 \mathrm{H}), 3.81(\mathrm{~d}$, $J=15.0 \mathrm{~Hz}, 4 \mathrm{H}), 4.62(\mathrm{~d}, J=15.0 \mathrm{~Hz}, 4 \mathrm{H}), 6.96-7.50(\mathrm{~m}, 16 \mathrm{H}) .7 .84-7.89$ $(\mathrm{m}, 4 \mathrm{H}):{ }^{3} \mathrm{C} \mathrm{NMR}\left(\mathrm{CS}_{2} / \mathrm{CDCl}_{3}, 100 \mathrm{MH}\right): \delta=40.88,41.56,42.67,53.37$. $79.45,99.82,126.86,126.91,128.24,128.47,130.65 .131 .86,133.08,134.97$, $135.42,136.34,136.52,137.81,141.12,141.23,141.31,142.36,142.83 .142 .89$. $143.10,143.27,143.49,143.78,144.01,144.32,144.50,144.55,144.60,144.70$. $144.76,144.89,146.04,146.35,146.47,146.54,147.36,147.40 .148 .63 .148 .87$; $\mathrm{UV} / \mathrm{Vis}\left(\mathrm{CHCl}_{3}\right): \lambda_{\max }\left(: \times 10^{-3} \mathrm{~L} \mathrm{~mol}^{-1} \mathrm{~cm}^{-1}\right)=699(0.2), 658(0.3), 637$ $(0.4), 607,445,422(4.9), 331,257(147.9) \mathrm{nm} ; \mathrm{IR}(\mathrm{KBr}): i=1493,1467$. $1438,1427,1378,1355,1331.1305,1275.1191,1167,1154,1112,1072.1032$. $1011,990,961,919,856,819,762,753,729,701 \mathrm{~cm}^{-1}$; FABMS: 1026.2.

11: ${ }^{1} \mathrm{H} \mathrm{NMR}\left(\mathrm{CS}_{2} / \mathrm{CDCl}_{3}, 300 \mathrm{MHz}\right): \delta=3.17(\mathrm{~s}, 2 \mathrm{H}), 3.47(\mathrm{~s}, 2 \mathrm{H}), 4.18(\mathrm{~d}$, $J=22.6 \mathrm{~Hz}, 2 \mathrm{H}), 4.33(\mathrm{~d}, J=22.6 \mathrm{~Hz}, 2 \mathrm{H}), 7.11-7.42(\mathrm{~m}, 10 \mathrm{H}):{ }^{13} \mathrm{C} \mathrm{NMR}$ $\left(\mathrm{CS}_{2} / \mathrm{CDCl}_{3}, 100 \mathrm{MHz}\right): \delta=42.51,44.97,45.19,56.25,126.74,126.77$. $128.35 .128 .42,131.18,131.62,135.71,136.46,136.52,136.75,138.59,139.09$. $139.37,139.67,139.85,140.70 .140 .92,141.18,141.24,141.31,141.88,142.96$. $142.98,143.61 .143 .68,143.73,144.11,144.49,144.77,145.07,145.08,145.37$. $145.76,145.80,146.17,146.64,147.05,147.82, ; \mathrm{UV} / \mathrm{Vis}\left(\mathrm{CHCl}_{3}\right): i_{\text {max }}$ $\left(: \times 10^{-3} \mathrm{~L} \mathrm{~mol}^{-1} \mathrm{~cm}^{-1}\right)=524(1.3), 427.329(27.4), 258$ (107.8) nm: IR $(\mathrm{KBr}): \tilde{v}=2096,1947,1655,1638,1600,1511,1493,1464.1444 .1405,1377$, $1354,1327,1290,1251,1220,1206,1187,1155,1133,1120,1072,1030,1003$. 917, 782, 749, 729, $701 \mathrm{~cm}^{\prime}$ '; FABMS: 970.8.

Thermolysis of 9: $\Lambda$ solution of $9(10 \mathrm{mg} .0 .01 \mathrm{mmol})$ in chlorobenzene $(10 \mathrm{~mL})$ was refluxed for $24 \mathrm{H}$. The mixture was cooled to room temperature and then analyzed by HPLC [Buckycluteher column, toluene: hexane $=2: 1$, flow ratc $=3 \mathrm{~mL} \mathrm{~min}^{-1}$, UV detector wavelength $=340 \mathrm{~nm}$. retention time (min)]: $C_{60}(1.6), 11(1.9), 8(2.0)$, and $\left.9(2.5)\right]$

Compounds 8 and 11 were treated in the same way. 
Acknowledgment: This work was supported by the National Science Council of the Republic of China.

Received: September 30, 1996 [F 479]

[1] a) M. Prato, Q. C. Li, F. Wudl, V. Lucchini, J. Am. Chem. Soc. 1993, 115, 1148 b) M. Takeshita, T. Suzuki, S. Shinkai, J. Chem. Soc. Chem. Commun. 1994 2587; c) C. J. Hawker, P. M. Saville, J. W. White, J. Org. Chem. 1994, 59, 3503 ; d) M. R. Banks, J. I. G. Cadogan, I. Gosney, P. K. G. Hodgson, P. R. R Langridge-Smith, J. R. A. Miller, A. T. Taylor, J. Chem. Sox. Chen. Commzis. 1995 885; e) G. Schick, T. Grösser, A. Hirsch, ibid. 1995, 2289 ; f) J. C. Hummelen, M. Prato, F. Wudl, J. Am. Chem. Soc. 1995, 117, 7003.

[2] a) T. Ishida, K. Tanaka, T. Nogami, Chem. Lett. 1994, 561; b) M. R. Banks, J. I. G. Cadogan, I. Gosney, P. K. G. Hodgson, P. R. R. Langridge-Smith D. W. H. Rankin, J. Chem. Soc. Chem. Commun. 1994, 1365: c) M. R. Banks, J. I. G. Cadogan, I. Gosney, P. K. G. Hodgson, P. R. R. Langridge-Smith J. R. A. Miller, A. T. Taylor, Tetrahedron Lett. 1994, 35, 9067; d) L.-L. Shiu, K.-M. Chien, T.-Y. Liu, T.-I Lin, G.-R. Her, S.-L. Huang, T.-Y. Luh, J. Chem Soc. Perkin Trans. 1, 1994, 23, 3355; e) M. Yan, S. X. Cai, J. F. W. Keana, J Org. Chem. 1994, 59, 5951; f) J. Averdung, J. Mattay, D. Jacovi. W. Abraham, Tetrahedron 1995, 51, 2543; g) J. Averdung, H. Luftmann, J. Mattay, K.-U Claus. W. Abraham, Tetrahedron Lett. 1995, 36, 2957; h) M. R. Banks, J. I. G Cadogan, I. Gosney, A. J. Henderson, P. K. G. Hodgson, W. G. Kerr, A Kerth, P. R. R. Langridge-Smith, J. R. A. Miller, A. R. Mount, J. A. Parkinson. A. T. Taytor, P. Thornburn, J. Chem. Soc. Chem. Commun. 1996, 507; i) A. B. Smith III, H. Tokuyama, Tetrahedron 1996, 52, 5257; j) J. Averdung,
H. Luftmann, I. Schlachter, J. Mattay, ibid. 1995, 51, 6977; k) J. Averdung, C. Wolff, J. Mattay, Tetrahedron Letl. 1996, 37, 4683: 1) J. Avcrdung, J. Mattay, Tetrahedron 1996, 52, 5407.

[3] T. Grösser, M. Prato, V. Lucchini, A. Hirsch, F. Wudl, Angew'. Chem. Int. Ed. Engl. 1995, 34, 1343.

[4] J. C. Hummelen, B. Knight, J. Pavlovich, R. Gonzálcz, F. Wudl, Seience 1995. $269,1554$.

[5] L. Echegoyen, private communication.

[6] a) L.-L. Shiu, K.-M. Chien, T.-Y. Liu, T.-I Lin, G.-R. Her, T.-Y. Luh, J. Chem Soc. Chem. Commun. 1995, 1159 ; b) C. K.-F. Shen, K.-M. Chien. C.-G. Juo G.-R. Her, T.-Y. Luh, J. Org. Chen. 1996, 61, 9242.

[7] G.-X. Dong, J.-S. Li, T.-H. Chan, J. Chem. Soc. Chem. Commun. 1995. 1725.

[8] I. Lamparth, B. Nuber, G. Schick, A. Skiebe, T. Grösser, A. Hirsch, Angew. Chem. Int. Ed. Engl. 1995, 34, 2257.

[9] G. Schick, A. Hirsch, H. Mauser, T. Clark, Chem. Eur. J. 1996, 2. 935.

[10] a) M. Rasinkangas, T. T. Pakkanen, T. A. Pakkanen, M. Ahlgrén, J. Rouvinen, J. Am. Chem. Soc. 1993, 115, 4901 ; b) C. C. Henderson, C. M. Rohlfing, R. A Assink, P. A. Cahill, Angew. Chem. Int. Ed. Engl. 1994, 33, 786; c) I. J. Mavunkal, Y. Chi, S.-M. Peng, G. H. Lee, Organometallic 1995, 14, 4454 d) A. L. Balch, D. A. Costa, B. C. Noll, M. M. Olmstead, J. Am. Chem. Soc $1995,117,8926$

[11] B. Nuber, F. Hampel, A. Hirsch, J. Chem. Soc. Chem. Commun. 1996, 1799.

[12] For a review, see: P. Scheiner in Selective Organic Transformations, Vol 2 (Ed: B. S. Thyagarajan), Wilcy-Interscience, New York, 1970, p 327.

[13] These two nitrogen-centered radicals may not exist at the same time. This intermediate is proposed for the sake of simplicity in order to explain the overall reaction. 